\title{
Correction
}

\section{Correction to: An efficient content based image retrieval using enhanced multi-trend structure descriptor}

\section{S. Sathiamoorthy ${ }^{1} \cdot$ M. Natarajan ${ }^{2}$}

Published online: 4 February 2020

(c) Springer Nature Switzerland AG 2020

Correction to: SN Applied Sciences (2020) 2:217 https://doi.org/10.1007/s42452-020-1941-y

Figure 1 in the original article was incorrect. The correct

Publisher's Note Springer Nature remains neutral with regard to Fig. 1 is shown below with the corrected part in red.

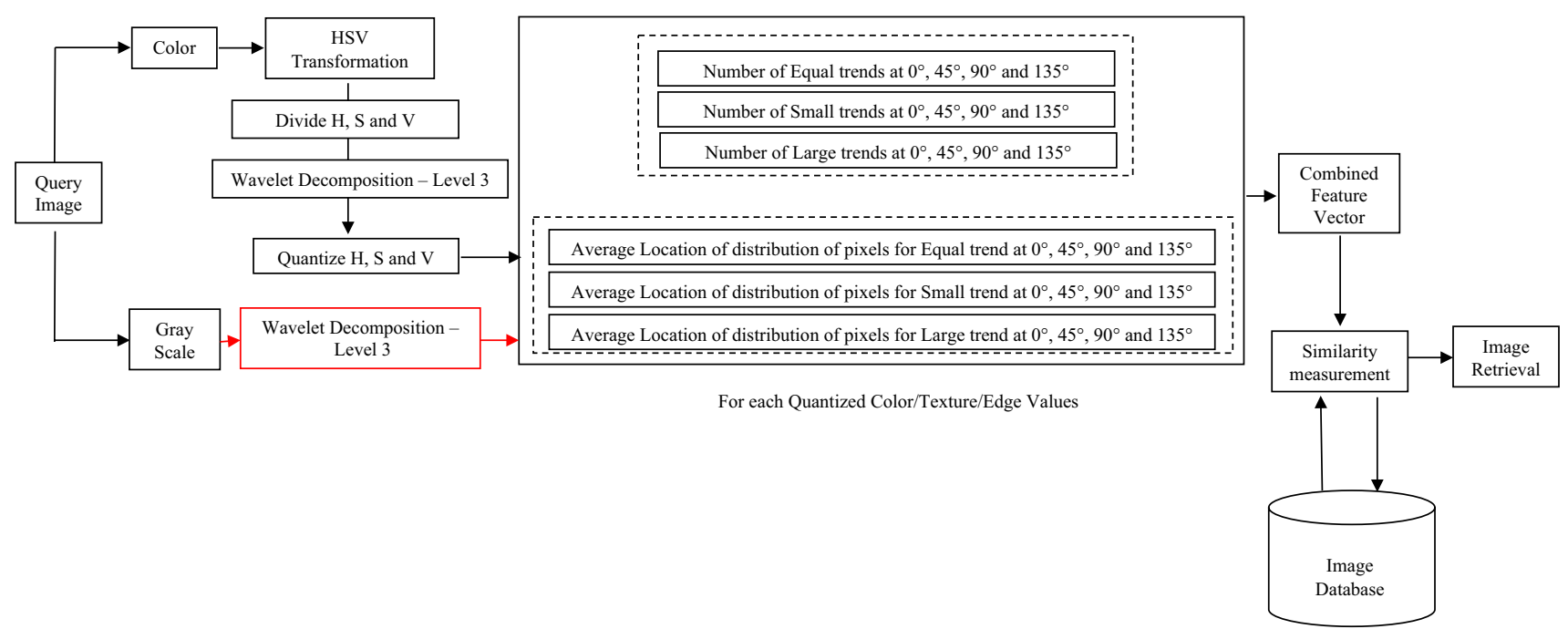

Fig. 1 Architecture of the proposed retrieval system

The original article can be found online at https://doi.org/10.1007/s42452-020-1941-y.

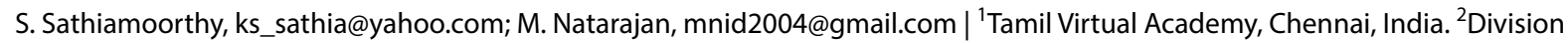
of Computer and Information Science, Annamalai University, Annamalai Nagar, India. 